\section{Commentary: Airway anomalies and congenital heart defects, a dangerous combination}

\author{
Jacob R. Miller, MD, and Pirooz Eghtesady, MD, PhD
}

Congenital heart defects (CHDs) and airway anomalies often occur as comorbid conditions. Although intuitively one would assume the presence of an airway anomaly would result in increased mortality, the precise impact has not been defined. In addition, when both anomalies require surgical correction, some advocate for a simultaneous approach, whereas others favor a staged approach. ${ }^{1,2}$ Lastly, the natural remaining follow-up question remains: which should be repaired first?

In this issue of the Journal, Riggs and colleagues ${ }^{3}$ have made a reasonable effort to answer some of these questions by using the Society of Thoracic Surgeons (STS) Congenital Heart Surgery Database. They identified nearly 200,000 operations for CHD, showing that airway anomalies, from tracheal stenosis to malacia, were present in $3.4 \%$. These airway anomalies were associated with more complex operations and therefore, not surprisingly, a worse outcome. When considering all patients with airway anomalies, including those who (presumably) did not need surgical intervention on their airway, the mortality rate was $6.4 \%$ versus $3.4 \%$ for patients without airway anomalies, although again, this represents unmatched data (ie, unequal distribution of STAT [The Society of Thoracic Surgeons-European Association for Cardio-Thoracic Surgery] categories).

Due to the limitations of this database query, the authors took a creative route to group their data. Specifically, they chose to break down airway anomalies into those with and without tracheal stenosis and those who did or did not require surgical intervention and compared them with those without airway abnormalities. When they considered the adjusted outcomes using a multivariable analysis of each subgroup,

From Washington University in St Louis School of Medicine/St Louis Children's Hospital, St. Louis, Mo.

Disclosures: The authors reported no conflicts of interest.

The Journal policy requires editors and reviewers to disclose conflicts of interest and to decline handling or reviewing manuscripts for which they may have a conflict of interest. The editors and reviewers of this article have no conflicts of interest.

Received for publication Nov 14, 2020; revisions received Nov 14, 2020; accepted for publication Nov 16, 2020; available ahead of print Nov 23, 2020.

Address for reprints: Pirooz Eghtesady, MD, PhD, St. Louis Children's Hospital, One Children's Place, Suite 5 South, St Louis, MO 63110 (E-mail: eghtesadyp@ wudosis.wustl.edu).

J Thorac Cardiovasc Surg 2021;161:1122-3

$0022-5223 / \$ 36.00$

Copyright (c) 2020 by The American Association for Thoracic Surgery

https://doi.org/10.1016/j.jtcvs.2020.11.058
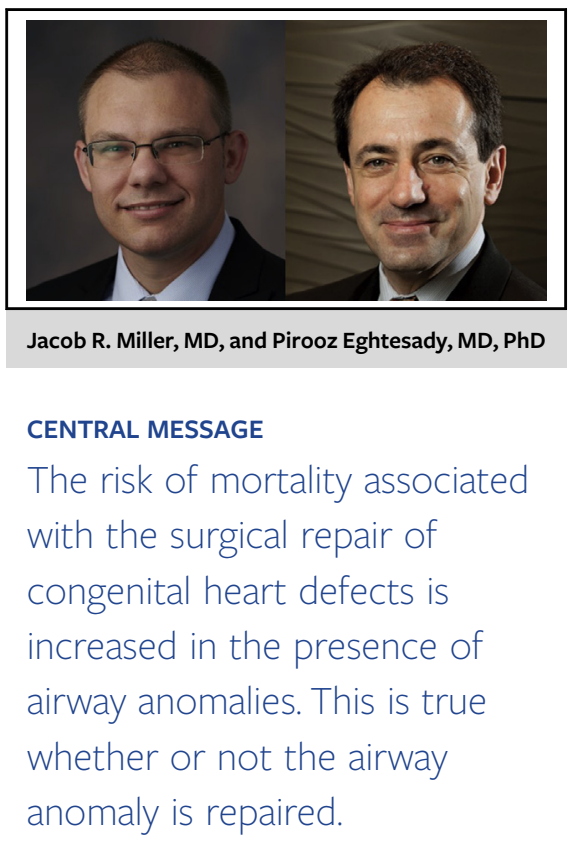

the adjusted odds of mortality for each group were tracheal anomaly other than tracheal stenosis with airway intervention: 4.07; tracheal stenosis with airway intervention: 3.7 ; tracheal stenosis without airway intervention: 1.5; airway malacia: 0.8; and other airway anomalies: 1.9. Sadly, for the first group $(n=145)$ with the greatest risk, we don't know what interventions were performed on the airway, except presumably the 34 with a diagnosis of tracheoesophageal fistula. In addition, surprisingly, 516 patients with tracheal stenosis did not undergo airway intervention, despite the STS definition being tracheal stenosis with greater than $50 \%$ obstruction of the lumen. Or was it perhaps not so severe and miscoded in some? And finally, these data suggest having airway malacia is somewhat protective!?

Clearly, any patient who underwent surgical intervention on their airway had an increased mortality. In addition, tracheal stenosis itself represented a significant comorbid condition, either repaired or if repair is determined to be "unnecessary." Beyond these general statements, there are many questions regarding patient selection and timing for airway intervention that are unable to be answered by the current study.

Importantly, some of the data from the authors study are sobering and surprising. For instance, the authors report an operative mortality of $14.4 \%$ for concomitant surgery for tracheal stenosis and CHD. This is in contrast to some excellent single-institution studies such as the one reported by Manning and colleagues. ${ }^{4}$ These disparate data show the value of database reports, highlighting the broader experience 
of the community. Clearly, to answer more granular questions requires more granular data. Hopefully, future versions of the STS database will allow for such investigations.

\section{References}

1. Ramaswamy M, Yeh YT, Varman R, McIntosh N, McIntyre D, Fedevych O, et al. Staging of surgical procedures in comorbid congenital tracheal stenosis and congenital cardiovascular disease. Ann Thorac Surg. 2020;109: 1889-96.
2. Loukanov T, Sebening C, Springer W, Ulmer H, Hagl S. Simultaneous management of congenital tracheal stenosis and cardiac anomalies in infants. $J$ Thorac Cardiovasc Surg. 2005;130:1537-41.

3. Riggs KW, Zafar F, Jacobs ML, Jacobs JP, Thibault D, Guleserian KJ, et al Tracheal surgery for airway anomalies associated with increased mortality in pediatric patients undergoing heart surgery: Society of Thoracic Surgeons database analysis. J Thorac Cardiovasc Surg. 2021;161:1112-21.e7.

4. Manning PB, Rutter MJ, Lisec A, Gupta R, Marino BS. One slide fits all: the versatility of slide tracheoplasty with cardiopulmonary bypass support for airway reconstruction in children. J Thorac Cardiovasc Surg. 2011;141:155-61.
See Article page 1112.

\section{Commentary: God is in the details!}

\section{T. K. Susheel Kumar, MD}

The negative relationship of congenital heart disease with airway anomalies has long been appreciated by health care providers. Recent studies have shown that both morbidity and mortality in children undergoing repair of congenital heart disease are significantly greater in those with airway anomalies. ${ }^{1,2}$ However, the wide spectrum of pathology within each group does not permit a simple generalization of this relationship. In this study, Riggs and colleagues $^{3}$ have sought to define this association in a more refined way using the Society of Thoracic Surgeons Congenital Heart Surgery Database. The authors are indeed to be commended for their efforts to answer long-overdue questions regarding quantification and stratification of the risks of airway intervention in children with heart defects. Notable strengths of the study include a large study population from multiple institutions, allowing for generalization of conclusions and stratification of risk of airway intervention in a way that can be easily applied by health care providers. The study will also serve as a solid reference for

\footnotetext{
From the Division of Congenital Cardiothoracic Surgery, Hassenfeld Children's Hospital at NYU Langone Health, New York, NY.

Disclosures: The author reported no conflicts of interest.

The Journal policy requires editors and reviewers to disclose conflicts of interest and to decline handling or reviewing manuscripts for which they may have a conflict of interest. The editors and reviewers of this article have no conflicts of interest.

Received for publication Nov 9, 2020; revisions received Nov 9, 2020; accepted for publication Nov 12, 2020; available ahead of print Nov 20, 2020.

Address for reprints: T. K. Susheel Kumar, MD, Department of Congenital Cardiothoracic Surgery, NYU Langone Health, New York, NY 10016 (E-mail: tksusheel. kumar@nyulangone.org).

J Thorac Cardiovasc Surg 2021;161:1123-4

$0022-5223 / \$ 36.00$

Copyright (c) 2020 by The American Association for Thoracic Surgery

https://doi.org/10.1016/j.jtcvs.2020.11.041
}

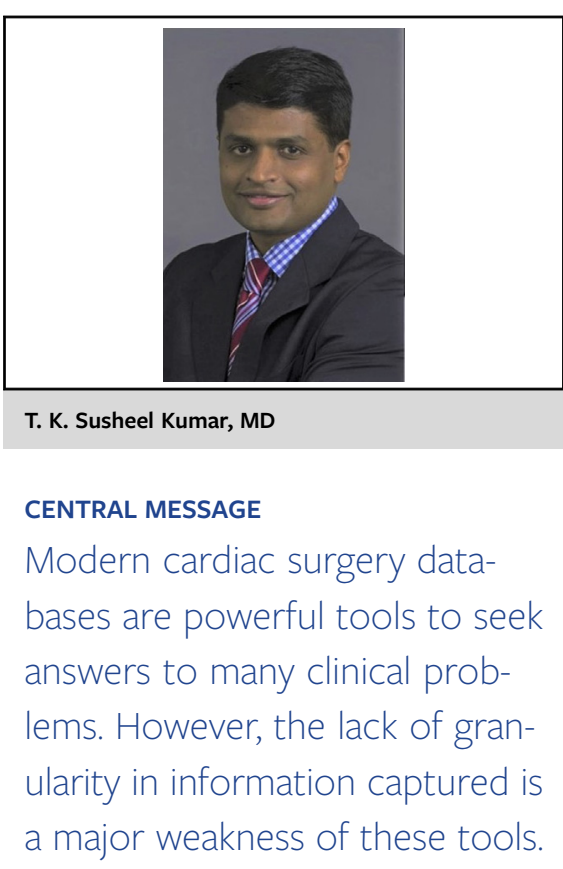

clinicians and

families involved in the care of this critical subset of patients.

However, the study falls short of expectations and leaves some crucial questions unanswered. There are no clues provided for recurring dilemmas in clinical practice, such as optimal timing of airway intervention; whether airway intervention should precede or follow cardiac intervention; optimal duration between the 2 interventions; and the level of airway support at which tracheostomy or other form of procedure should be considered, among others. In the authors' defense, the Society of Thoracic Surgeons Congenital Heart Surgery Database does not have provisions to capture this sort of granular information, thereby highlighting the fact that large databases with multicenter information are not the answer to all pending clinical questions. Single institutional studies with more granular 